\title{
Evaluation of the therapeutic results of actinic keratosis treated with topical $5 \%$ fluorouracil by reflectance confocal laser microscopy: preliminary study*
}

\author{
Priscila Ishioka ${ }^{1,2}$ \\ Sarita Bartholomei Rodrigues ${ }^{2}$ \\ Sérgio Henrique Hirata ${ }^{1}$
}

\author{
Marcus Maia ${ }^{2}$ \\ Alessandra Cristina Marta²
}

DOI: http:/ / dx.doi.org/10.1590/abd1806-4841.20153437

\begin{abstract}
A bstract: Topical treatment for actinic keratosis with 5\% fluorouracil has a recurrence rate of $54 \%$ in 12 months of follow-up. This study analyzed thirteen actinic keratoses on the upper limbs through confocal microscopy, at the time of clinical diagnosis and after 4 weeks of treatment with fluorouracil. After the treatment was established and evidence of clinical cure was achieved, in two of the nine actinic keratoses, confocal microscopy enabled visualization of focal areas of atypical honeycomb pattern in the epidermis indicating therapeutic failure. Preliminary data suggest the use of confocal microscopy as a tool for diagnosis and therapeutic control of actinic keratosis.
\end{abstract}

Keywords: Fluorouracil; Keratosis, actinic; Microscopy, confocal

Actinic keratosis (AK) is a pre-neoplastic lesion with a transformation degree into squamous cell carcinoma of 0.1 to $20 \%$. ${ }^{1,2}$ Fluorouracil (FU), one of the therapeutic alternatives for $\mathrm{AK}$, presented a recurrence frequency of $54 \%$ in 12 months of follow-up. ${ }^{3}$ Topical use of 5-FU for 2 to 4 weeks has a recommendation degree II and a category B level of evidence with $96 \%$ clinical rate and $67 \%$ histological rate of cure. ${ }^{4,5}$

With the goal of increasing diagnostic accuracy and therapeutic control of AK, non-invasive methods were described such as the use of dermoscopy and recently reflectance confocal laser microscopy (RCLM). RCLM is a non-invasive examination, which allows the visualization in vivo of structures and cells with similar resolution to histology. ${ }^{6}$

RCLM has a sensitivity of $80 \%$ and specificity of 98.6\% for the diagnosis of AK. ${ }^{7}$ RCLM of AK is characterized by the finding of small ruptures in the corneal layer and the presence of isolated keratinocytes, which are visualized as polygonal and hyper refractory. Parakeratosis is represented by the presence of nucleated cells with dark center and marked peripheral halo. In the granular and spinous layer an architectural disarray is observed (atypical honeycomb) with nucleated round cells of varied sizes, which histologically represent the dysplasia of keratinocytes. In the upper dermis, round dilated vessels and moderately refractory linear structures are observed, which correspond to solar elastosis. ${ }^{8,9}$

Ulrich et al in 2010 described the applicability of RCLM in the therapeutic follow-up of AK with imiquimod and emphasized the importance of the method in the recognition of subclinical actinic lesions. ${ }^{10}$

These data stimulated us to develop a similar and unprecedented study, with the objective of analyzing, through RCLM, the response of AK treatment

Received on 08.02.2014

Approved by the Advisory Board and accepted for publication on 22.04.2014

Work performed at the confocal microscopy outpatient clinic of the Dermatology Department, Santa Casa de Misericórdia de São Paulo - São Paulo (SP), Brazil.

Financial Support: None.

Conflict of Interest: None.

Universidade Federal de São Paulo (UNIFESP) - São Paulo (SP), Brazil.

Santa Casa de Misericórdia de São Paulo - São Paulo (SP), Brazil.

C2015 by Anais Brasileiros de Dermatologia 
with FU. A preliminary study was conducted at the confocal microscopy outpatient clinic of the dermatology department of the charity hospital Santa Casa de Misericórdia de São Paulo - SP, from January to December of 2013, after approval by the research ethics committee. Thirteen AK on the upper limbs of seven patients, clinically diagnosed, were recorded and analyzed through RCLM, at the time of clinical diagnosis and again after 4 weeks of treatment with $5 \% \mathrm{FU}$ cream divided into 2 cycles. Each cycle corresponded to 2 weeks of occlusive FU every 12 hours, followed by 2 weeks with almond oil. Post-treatment imagery were obtained from clinically cured AK patients. Capture of clinical digital images were performed with an Iphone $4 S^{\circledR}$ camera. Skin marking of lesions was made with a ballpoint pen and panoramic photograph of the region. For the RCLM examination, a Vivascope $1500^{\circledR}$ device was used. The detailed description of the technique and device has already been reported in other publications. Transversal $5 \times 5 \mathrm{~mm}$ images were captured of all epidermal strata (corneal, granular and spinous) and of superficial dermis. Each captured image was analyzed by two dermatologists, simulta- neously, experienced in confocal microscopy, before and after introduction of FU, as to the presence of the following characteristics: rupture of corneal layer with nucleated polygonal cells; epidermis (granular and spinous layers) in a honeycomb arrangement (atypical) and round nucleated cells; dilated vessels, round and solar elastosis in dermis. Exclusion criteria: hypertrophic AK and/or with clinical suspicion of malignant transformation.

The thirteen AK belonged to patients of Fitzpatrick's phototypes I and II, with mean age of 69.7. RCLM of AK before establishing the treatment, in all patients, revealed granular and spinous layers with $n$ irregular honeycomb and nucleated round cells (Figure 1). A corneal layer with ruptures and presence of polygonal cells was observed, isolated, in $77 \%$ of the cases and revealed only $31 \%$ of lesions as having solar elastosis and rounded dilated vessels in the dermis. Two patients (four AK) were excluded from the study because they developed contact dermatitis to FU. Post-treatment: RCLM of the nine AK, submitted to treatment and with clinical cure, demonstrate corneal layer without changes, absence of ruptures

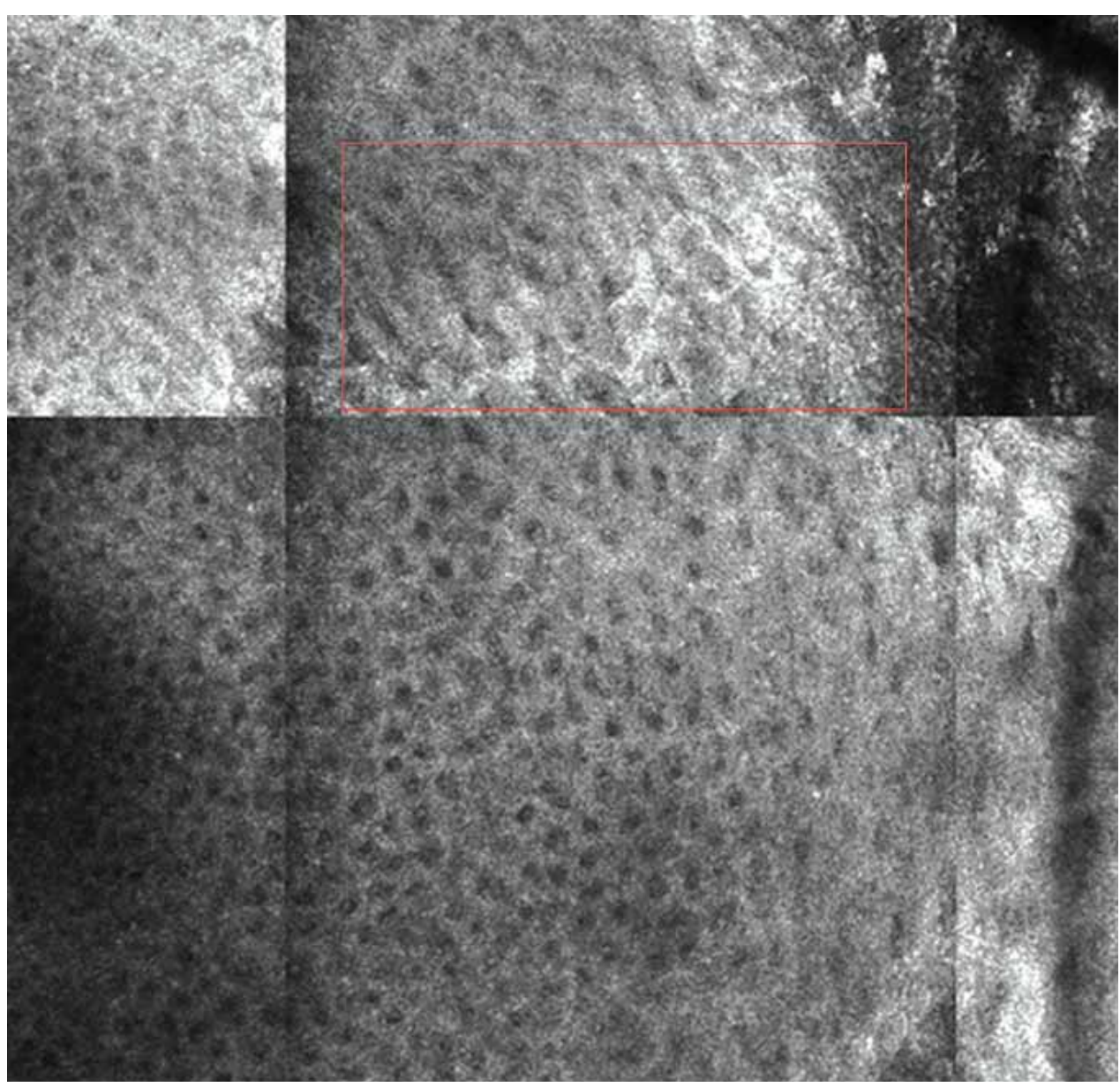

\section{Figure 1:}

Image of confocal microscopy of actinic keratosis with architectural disarray in the granular and spinous layers (atypical honey$\mathrm{comb}$ ) with pleomorphism of keratinocytes 


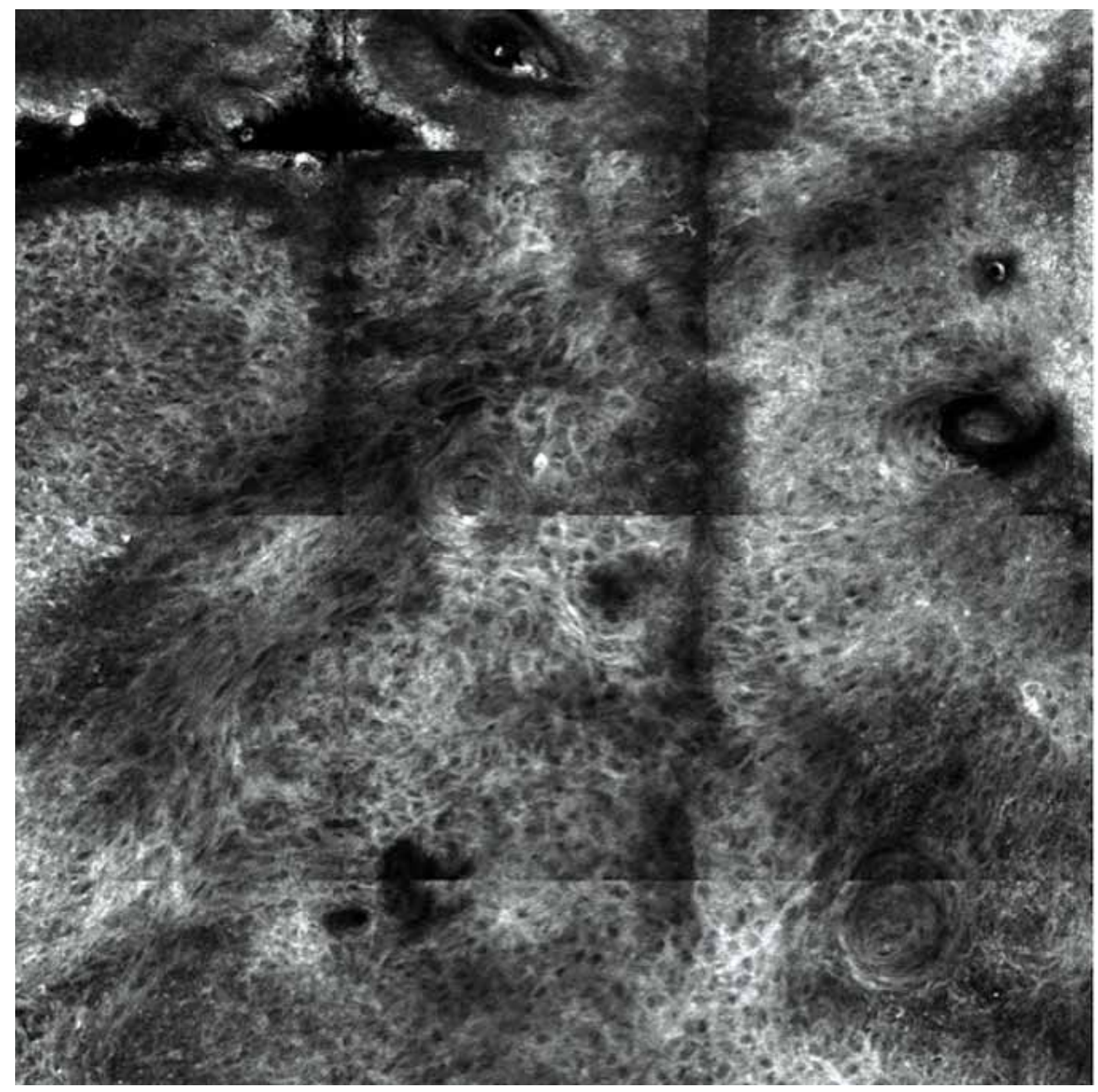

\section{FIGURE 2:}

Image of confocal microscopy of actinic keratosis treated with topical $5 \%$ fluorouracil demonstrating focal area of atypical honeycomb and/or nucleated polygonal cells. In seven of the nine cases treated, it was visualized regular granular and spinous layers, typical, without rounded cells. In two AK, small isolated areas of atypical honeycomb with rounded cells in the granular and spinous layers (Figure 2) were observed by means of RCLM. The presence of dilated vessels and of elastosis in the dermis was observed in $11 \%$ and $22 \%$, respectively.

In this study, the RCLM of AK presented an atypical honeycomb with rounded cells, located in the epidermis in $100 \%$ of the cases. This data reaffirms that the presence of architectural disarray and cellular pleomorphism are the best predictors for the diagnosis of AK, also described by Ulrich et al. ${ }^{7,9}$ The finding of solar elastosis and rounded vessels in only $31 \%$ of the cases may be due to presence of adherent scales on the surface, which makes the visualization of deeper structures difficult. Ulrich et al in 2008 also observed low concordance among the examiners in the analysis of dermal changes when evaluating $46 \mathrm{AK}$ patients. ${ }^{7}$ All treated AK achieved clinical cure, and in two of nine lesions, RCLM allowed the visualization of focal areas of atypical honeycomb, with atypical cells, in the granular and spinous layers, suggesting therapeutic failure.

This protocol is a work in progress, however, since the preliminary data suggested the use of RCLM as a tool for diagnosis and therapeutic control of AK, in our judgment this prior notice would be of scientific importance. 


\section{REFERENCE}

1. Callen JP, Bickers DR, Moy RL. Actinic keratoses. J Am Acad Dermatol. 1997;36:650-3

2. Glogau RG. The risk of progression to invasive disease. J Am Acad Dermatol. 2000;42:23-4.

3. Krawtchenko N, Roewert-Huber J, Ulrich M, Mann I, Sterry W, Stockfleth E. A randomised study of topical $5 \%$ imiquimod vs. topical 5 -fluorouracil vs. cryosurgery in immunocompetent patients with actinic keratoses: a comparison of clinical and histological outcomes including 1-year follow-up. Br J Dermatol. 2007:157:34-40.

4. Gupta AK, Davey V, Mcphail H. Evaluation of the effectiveness of imiquimod and 5-fluorouracil for the treatment of actinic keratosis: Critical review and metaanalysis of efficacy studies. J Cutan Med Surg. 2005;9:209-14.

5. Euroderm.org [Internet]. Sterry W, Griffiths C, Korting HC. Guidelines for the Management of Actinic Keratoses. European Dermatology Forum. EDF Guidelines for Dermatology in Europe. 2011. [cited 2014 Jan 10]. Available from: http://www. euroderm.org/index.php/edf-guidelines

6. Rajadhyaksha M, González S, Zavislan JM, Anderson RR, Webb RH. In vivo confocal scanning laser microscopy of human skin Il: advances in instrumentation and comparison with histology. J Invest Dermatol. 1999;113:293-303.

7. Aghassi D, Anderson RR, González S. Confocal laser microscopic imaging of actinic keratoses in vivo: a preliminary report. J Am Acad Dermatol. 2000;43:42-8.

8. Ulrich M, Maltusch A, Rius-Diaz F, Röwert-Huber J, González S, Sterry W, et al. Clinical applicability of in vivo reflectance confocal microscopy for the diagnosis of actinic keratoses. Dermatol Surg. 2008;34:610-9.

9. Rishpon A, Kim N, Scope A, Porges L, Oliviero MC, Braun RP, et al. Reflectance confocal microscopy criteria for squamous cell carcinomas and actinic keratoses. Arch Dermatol. 2009;145:766-72.

10. Ulrich M, Krueger-Corcoran D, Roewert-Huber J, Sterry W, Stockfleth E, Astner S. Reflectance confocal microscopy for noninvasive monitoring of therapy and detection of subclinical actinic keratoses. Dermatology. 2010;220:15-24.

\author{
M AILING ADDRESS: \\ Priscila Ishioka \\ A v. Jabaquara 3060 cj 400/401 \\ 04046-500 - São Paulo - SP \\ Brazil \\ E-mail: pishioka@uol.com.br
}

How to cite this article: Evaluation of the therapeutic results of actinic keratosis treated with topical $5 \%$ fluorouracil by reflectance confocal laser microscopy: preliminary study. Ishioka P, Maia M, Rodrigues SB, Marta AC, Hirata SH. An Bras Dermatol. 2015; 90(3):426-9. 